\title{
Corrigendum: Larger mitochondrial DNA than Y-chromosome differences between matrilocal and patrilocal groups from Sumatra
}

Ellen Dröfn Gunnarsdóttir, Madhusudan R. Nandineni, Mingkun Li, Sean Myles, David Gil, Brigitte Pakendorf \& Mark Stoneking

Nature Communications 2:228 doi: 10.1038/ncomms1235 (2011); Published 8 Mar 2011; Updated 7 Feb 2012.

In Supplementary Table S2 of this Article, some of the sampling locations are incorrect, as follows:

Sample IDs Bes10, Bes22, Bes23, Bes24, Bes4, Bes5, Bes6, Bes8 and Bes9 should be Pelaragan.

Sample ID Bes11 should be Merpayang.

Sample ID Bes12 should be Pauna Salak.

Sample IDs Bes13, Bes19 and Bes21 should be Jemaring.

Sample IDs Bes2 and Bes38 should be Pagaralam.

Sample IDs Bes27, Bes28, Bes29, Bes30, Bes31, Bes32, Bes33 and Bes34 should be Jambat Akar.

Sample IDs Bes35, Bes36 and Bes37 should be Jangkar.

Sample IDs Smd17, Smd2, Smd18, Smd19, Smd20, Smd21, Smd22, Smd23, Smd24, Smd25 and Smd9 should be Semende. 